\title{
DISTRIBUICÃO DE ELEMENTOS RADIOATIVOS NO GRANITO SERRA DO CARAMBEÍ, PARANÁ, BRASIL
}

\author{
CRISTINA VALLE PINTO-COELHO* e KÁTIA NORMA SIEDLECKI*
}

\begin{abstract}
RADIOACTIVE ELEMENTS DISTRIBUTION IN THE SERRA DO CARAMBEÍ GRANITE, PARANÁ, BRAZIL. In the Serra do Carambeí Granite, the uranium present in the rock in anomalous concentration is hosted, preferentially, in accessory mineralogical phases-zircon, xenotime, magnetite and ilmenite, and, in lesser proportion, in the essential minerals of the rock-potassium feldsparand also iron oxydes/hydroxydes and alterated biotite. Optical petrography, autorradiomicrography, scanning electronic microscopy, and the utilization of correlation matrixes and the respective dendrograms revealed a distribution of radioctive elements basically controlled by autometassomatic, tardi/pos-magmatic or supergene processes. Intrusive felsic dikes in the Serra do Carambeí Granite have radioelement concentration level approximately four times higher than the enclosing granite, where uranium as well as thorium is preferentially found in metamictized accessory minerals - zircon and allanite. The concentration in total $\mathrm{U}_{3} \mathrm{O}_{8}$ of the Serra do Caramber Granite varies from 5 to $26 \mathrm{ppm}$, with an average of $9.9 \mathrm{ppm}$. Soluble uranium representing $68 \%$ of the total is ascribed to intersticial and secondary phases. Fixed uranium, corresponding to $32 \%$ of total uranium, is, in this granite, fixed in resistate accessory minerals. The average soluble U/total $U$ ratio is 0.69 ; whereas surface rocks have this value around 0.57 and those of the sub-surface, 0.71 . In the felsic dikes the concentration in total $\mathrm{U}_{3} \mathrm{O}_{8}$ varies from 18 up to $56 \mathrm{ppm}$, with an average of about $34.2 \mathrm{ppm}$. In these rocks, a correlation of colour with the distribution of radioelements was noticed, in such a way that those with brown colour showed higher proportions of $\mathrm{U}_{3} \mathrm{O}_{8}(\overline{\mathrm{x}}=39.5 \mathrm{ppm})$ than the greyish ore $(\overline{\mathrm{x}}=21 \mathrm{ppm})$. Soluble uranium corresponds to $59.4 \%$ of the whole and fixed uranium to $40.6 \%$, relating themselves, respectively, to intersticial and secondary phases and to accessory minerals such as zircon and allanite. Average soluble U/total U ratio lies around 0.60 .
\end{abstract}

\begin{abstract}
RESUMO No Granito Serra do Carambeí o urânio, presente na rocha em concentraçōes anômalas em relação aos granitos enriquecidos em sílica comumente citados na literatura especializada, localiza-se, preferencialmente, em fases mineralógicas acessórias - zircão, xenotima, magnetita e ilmenita e, em menores proporçōes, associa-se à mineralogia essencial da rocha - feldspato potássico - e ainda a бxidos/hidróxidos de ferro e biotita alterada. Estudos de petrografia ótica, autorradiomicrografia, microscopia eletrônica de varredura e a utilização de matrizes de correlação e respectivos dendrogramas revelaram que a distribuição de elementos radioativos é controlada basicamente por processos autometassomáticos, tardi/pós-magmáticos ou supergênicos. Diques félsicos, intrusivos no Granito Serra do Carambef, exibem concentraçōes em radioelementos aproximadamente quatro vezes superiores à da sua encaixante, onde tanto o urânio quanto o tório localizam-se, preferencialmente, em minerais acessórios metamictizados - zircão e allanita. A concentração em $\mathrm{U}_{3} \mathrm{O}_{8}$ total do granito varia de 5 a $26 \mathrm{ppm}$, cuja média situa-se em torno de 9,9 ppm. O urânio solúvel representa $68 \%$ do total e relaciona-se às fases intersticiais e secundárias. O urânio fixo, correspondente a $32 \%$ do urânio total, permanece, neste granito, aprisionado em minerais acessórios resistatos. A razão U solúvel/U total média é da ordem de 0,69 , onde rochas de superfície têm este valor em torno de 0,57 e as de subsuperfície 0,71 . Nos diques félsicos a concentração em $\mathrm{U}_{3} \mathrm{O}_{8}$ total varia de 18 a $56 \mathrm{ppm}$, com a média situando-se por volta de $34,2 \mathrm{ppm}$. Observou-se nestas rochas uma influência da coloração na distribuição de radioelementos, sendo que aquelas com coloração castanha exibiam maiores teores de $\mathrm{U}_{3} \mathrm{O}_{8}-\overline{\mathrm{x}}=39,5 \mathrm{ppm}-$ do que as acinzentadas $-\overline{\mathrm{x}}=21$ ppm $\mathrm{U}_{3} \mathrm{O}_{8}$. O urânio solúvel corresponde a $59,4 \%$ do total e o urânio fixo a $40,6 \%$, relacionando-se, respectivamente, a fases intersticiais e secundárias e a minerais acessórios como zircão e allanita. A razão U solúvel/U total média situa-se em torno de 0,60 .
\end{abstract}

\begin{abstract}
INTRODUÇÃO Não existe na literatura geológica especializada um consenso quanto às principais características de um granito uranífero. A natureza distinta do material parental, as mudanças no ambiente geotectônico, bem como transformações tardi a pós-magmáticas sofridas por determinado corpo granítico, fazem seu quimismo ser obliterado, dificultando, conseqüentemente, seu enquadramento num sistema classificatório único.

Segundo Darnley (1982), um granito para ser classificado como uranífero deve ter um teor de urânio no mínimo duas vezes superior ao clarke deste elemento, ou seja, $8 \mathrm{ppm}$, considerando-se o clarke de $4 \mathrm{ppm}$. A existência de mineralização não constitui único critério seguro para a definição do granito como uranífero; por outro lado, são comuns rochas graníticas com teores médios acima de 8 ppm que não se apresentam mineralizadas. Observa-se, ainda, uma tendência geral deste elemento em aumentar com o grau de diferenciação, em que as variedades litológicas mais ricas em sílica apresentam os conteúdos mais elevados em urânio (Turovskii 1957, Wedepohl 1969).
\end{abstract}

Considerando-se o teor de 8 ppm como o mínimo exigido para a especialização de um granito, o Serra do Carambeí, com conteúdo médio de $9,9 \mathrm{ppm}$ de $\mathrm{U}_{3} \mathrm{O}_{8}$, poderia ser classificado como tal, ressalvando-se, entretanto, o fato de não terem sido detectadas mineralizações uraníferas significativas neste corpo, como se verá.

PROCEDIMENTOS ANALÍTICOS A identificação dos sítios preferenciais de localização do urânio no plúton em questão foi feita utilizando-se microscopia eletrônica de varredura (MEV), autorradiomicrografia e matrizes de correlação entre o urânio e os componentes químicos do granito. As amostras estudadas, obtidas tanto em superfície quanto em subsuperfície, foram analisadas por MEV por $\mathrm{L}$. Izoret do Bureau de Recherches Géologiques et Minières (BRGM, França), pela técnica de elétrons retrodifundidos. $\mathrm{O}$ teste autorradiomicrográfico foi realizado por K. Fuzikawa das Empresas Nucleares Brasileiras S.A. (Nuclebrás), Escritório Regional de Belo Horizonte, empregando-se o filme de nitrato de celulose $\mathrm{CN}-85$ da Kodak. As amostras 
analisadas por este método ficaram expostas ao detector durante um período de 57 dias, sendo o detector plástico, após a exposição, tratado em solução de $\mathrm{NaOH}, 2,5 \mathrm{~N}$, à temperatura de $60^{\circ} \mathrm{C}$ por um período de 30 minutos. A descrição detalhada desta técnica pode ser encontrada em Brandão (1984), Bowie (1951), Kwinta et al. (1980), Houston \& Jefferies (1981), Khadduri (1982) e Coppens et al. (1979).

A determinação analítica dos elementos radioativos foi feita por: a. M.P. Ferreira, do Centro de Desenvolvimento da Tecnologia Nuclear (CDTN Nuclebrás), pelo método de nêutrons retardados, para $\mathrm{U}_{3} \mathrm{O}_{8}$ total; b. C.C. Murta (CDTN), da Nuclebrás, pela fluorescência de raios X para $\mathrm{ThO}_{2}$; e c. J.S. Lima (Nuclebrás, Escritório Regional de Curitiba), por fluorimetria para $\mathrm{U}_{3} \mathrm{O}_{8}$ solúvel. As sondagens foram realizadas pela Comissấo Nacional de Energia Nuclear (CNEN), durante os anos de 1972 e 1973, mediante convênio firmado com a Companhia de Pesquisa de Recursos Minerais (CPRM), com objetivo de se prospectarem áreas radioanômalas na borda SW do Granito Serra do Carambeí.

\section{SITUAÇÃO GEOLÓgICA REGIONAL Na área} circunvizinha ao Granito Serra do Carambeí afloram unidades litologicas representadas pelo Complexo Granítico Cunhaporanga, de idade proteroz6ica média a superior, a seqüência vulcânica ácida eopaleozóica do Grupo Castro e os arenitos devonianos da Formaçáo Furnas (Fig. 1). Todo este conjunto se encontra indiscriminadamente cortado por diques de rochas básicas relacionadas ao vulcanismo toleítico ocorrido em tempos jurássico-cretáceos. $\mathrm{Na}$ borda $\mathrm{SW}$ do granito em discussáo, ocorrem diques félsicos pouco espessos de rochas com composição riolítica, ou seja, rochas ácidas altamente evoluídas, textural e mineralogicamente semelhantes a riolitos, diferenciadas do magma originário do granito hospedeiro. Trata-se de rochas formadas a partir do líquido leucocrático final do processo de cristalização magmática e equivalem ao que autores franceses (v.g. Charoy 1979) denominam elvans. Exibem concentrações anômalas em radioelementos, além de outros elementos-traços como $\mathrm{Nb}, \mathrm{Y}$, $\mathrm{Zr}$, Sn e F (Pinto-Coelho 1986).

Apenas o Granito Serra do Carambeŕ e os diques félsicos nele intrusivos mostram concentraçōes anômalas em elementos radioativos, tendo as demais unidades litologicas teores de urânio e tório equivalentes ao clarke desses elementos para cada grupo de rocha, seja granítica, seja vulcânica ou sedimentar. Relaçöes de campo, mineralogia, petrografia e petroquímica das unidades associadas e circunvizinhas ao Granito Serra do Carambeí são discutidas em Pinto-Coelho (op. cit.).

\section{CARACTERÍSTICAS PETROGRÁFICAS, PETROQUÍ- MICAS E DISTRIBUIÇÃO DOS TIPOS DE ROCHAS.} Granito Serra do Carambel Representa um plúton litologica e estruturalmente homogêneo, inscrito no Complexo Granítico Cunhaporanga, de idade do Proterozóico Superior, com formato grosseiramente retangular alongado e disposto segundo direção NE-SW em área aproximada de $33 \mathrm{~km}^{2}$ (Fig. 1). A única variedade litológica presente é um granito equigranular médio a grosso $(2-6 \mathrm{~mm})$, iśtropo, coloração rósea, com pequenas variaçóes locais devidas, sobretudo, à superimposição de efeitos cisalhantes. Esta fácies magmática primária, representada pelo granito hololeucocrático, caracteriza-se pela presença de feldspato potássico (microclínio fortemente ordenado, com triclinicidade media de 0,94 ) intensamente micropertitizado, quartzo e porcentagem de biotita inferior a $5 \%$, o que permite classificá-lo como alaskito. Acessoriamente, ocorrem zircão, xenotima, apatita, pirita, magnetita martitizada, hematita, fluorita e titanita; minerais secundários são epídoto, clorita, moscovita e carbonato.

As características petrograficas do granito em discussăo permitem enquadrá-lo no tipo hypersolvus de Tuttle \& Bowen (1958), marcado pela existência de uma única fase feldspática, estando ausente $o$ plagioclásio individualizado. Sua composição modal coloca-o no campo 2 dos alcali-feldspato granitos de Streckeisen (1976): pertita-granito. No diagrama multicatiónico $R_{1}-R_{2}$ de De La Roche et al. (1980), todas as amostras analisadas se dispõem no campo de álcali-granitos (Pinto-Coelho 1986). Foram analisados dois grupos de amostras referentes a este granito: o primeiro, de amostras de superfície, aparentemente frescas, coletadas em afloramentos e em pedreiras; e o segundo, de amostras de subsuperfície, coletadas em testemunhos de sòndagens cujas profundidades variaram de 18,90 a $83,25: \mathrm{m}$. O estudo comparativo destes dois grupos de rochas revelou a existência de importantes variaçōes composicionais, sobretudo nos elementos maiores, atribuídas a atuação de fenômenos intempericos (Pinto-Coelho op. cit.). $\mathrm{O}$ urânio, à semelhança dos 6 xidos principais, tambem mostra comportamentos distintos em amostras de superfície e subsuperfície, sendo, entretanto, tal variação menos acentuada que nos demais componentes químicos do granito. Rochas de superfície têm concentraçóes em $\mathrm{U}_{3} \mathrm{O}_{8}$ total que variam de 5 a $12 \mathrm{ppm} e$, nas de subsuperfície, a variação se faz entre 4 e $26 \mathrm{ppm}$ (Tab. 1); a média para os dois grupos de rochas é de $9,9 \mathrm{ppm} . \mathrm{O} \mathrm{U}_{3} \mathrm{O}_{8}$ solúvel representa $68 \%$ do urânio total contido na rocha, $\mathrm{U}_{3} \mathrm{O}_{8}$ sendo o restante (32\%) representado pelo $\mathrm{U}_{3} \mathrm{O}_{8}$ fixo. $\mathrm{A}$ razão $U$ solúvel/U total média para os dois grupos de rochas é da ordem de 0,69 . As amostras de superfície têm este valor em torno de 0,57 e as de subsuperfície, 0,71, indicando, assim, lixiviaçẫo parcial do urânio solúvel por processos intempéricos. $O$ torio, em todas as amostras analisadas, situou-se abaixo do limite inferior de deteç̧ão do método analítico utilizado.

A adoção de criterios puramente ponderais para a definição da metalogenia de uma rocha pode levar ao estabelecimento de parâmetros téricos que năo se coadunam com a realidade geológica prática. Ao se considerar, por exemplo, apenas o teor de urânio como suficiente para discriminar sua especialização, o Granito Serra do Carambeí equivaler-se-ia metalogeneticamente aos leucogranitos do Maciço de São Silvestre, França, cuja concentração de $\mathrm{U}_{3} \mathrm{O}_{8}$ oscila entre 8,7 e 21,1 ppm (Moreau 1977).

Não obstante os teores anômalos, não se detectou, até o momento, qualquer tipo de mineralização uranifera, estando o elemento concentrado em fases mineralogicas acessórias zircão, xenotima e magnetita - e em fases intersticiais ou intergranulares, adsorvidos a óxidos/hidróxidos de ferro.

Alem de disseminaçōes anômalas de urânio, para originar mineralizações são necessários também processos concentradores do metal, sejam eles de natureza tardi a pós-magmática ou intempérica, a fím de que a rocha seja considerada metalogeneticamente especializada, o que não foi observado nesta rocha (Pinto-Coelho op. cit.).

Diques félsicos associados $\mathrm{Na}$ borda $\mathrm{SW}$ do Granito Serra do Carambeí e, mais raramente, no contato NE, ocorrem diques de rochas rioliticas, que ostentam espessuras médias em torno de alguns poucos centímetros e máxima de $25 \mathrm{~cm}$, com direçöes, por vezes, ortogonais entre si. Essas rochas se apresentam fortemente intemperizadas no campo, e este fato, aliado à pequena espessura dos diques, inviabilizou a comparação entre amostras de superfície e subsuperfície, à semelhança do que foi feito para a sua encaixante. São rochas holocristalinas, com estrutura is 6 tropa, coloraçäo castanha e acinzentada, mais raramente verde, textura porfirítica, representada por fenocristais de quartzo bipiramidal que chegam a atingir $0,5 \mathrm{~cm}$ de comprimento, imersos em matriz afanítica de composição quartzo-feldspática. Ao microscópio, mostram fenocristais de quartzo, secundariamente feldspato potássico (microclínio) em matriz cripto a microcristalina, 


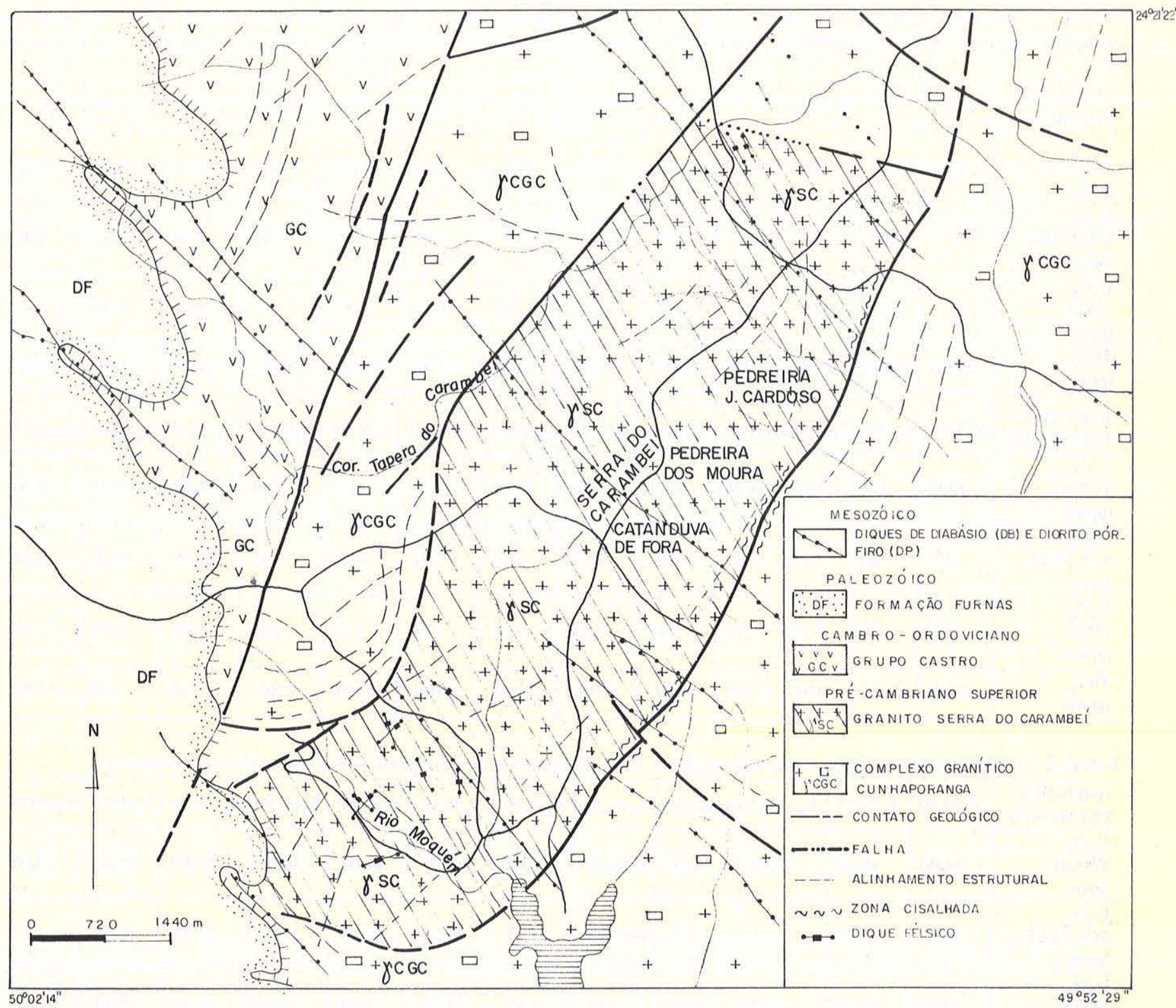

Figura 1-Mapa geologico simplificado da área do Granito Serra do Carambel, Paraná

constituída por grãos desses minerais, além de plagioclásio (albita). Biotita, turmalina, fluorita, hematita, magnetita, pirita, galena e ilmenita são acessórios freqüentes.

A co-geneticidade entre os diques félsicos e o granito hospedeiro é confirmada pelo padrão de distribuição de elementos terras-raras. $\mathrm{O}$ espectro obtido para essas rochas é essencialmente o mesmo, marcado por forte anomalia negativa de $\mathrm{Eu}$, diminuição em terras-raras leves e enriquecimento relativo em terras-raras pesadas (Pinto-Coelho \& Marini 1986).

Os diques apresentam quimismo similar ao do granito, no que se refere a elementos maiores; quanto aos elementos-traços, ( $\mathrm{Pb}, \mathrm{Zn}, \mathrm{Ba}, \mathrm{Li}, \mathrm{Zr}, \mathrm{Rb}, \mathrm{Nb}, \mathrm{Y}, \mathrm{Sn}, \mathrm{U}$ e Th), verifica-se nítido enriquecimento comparativamente à encaixante (Pinto-Coelho 1986). A concentração de $\mathrm{U}_{3} \mathrm{O}_{8} \mathrm{e}$ $\mathrm{ThO}_{2}$ para rochas de subsuperfície é mostrada na Tabela 2.

Um aspecto interessante dos diques anômalos, que só pôde ser caracterizado pelo estudo em amostras de testemunhos de sondagem, é a variação na coloração, intimamenté relacionada à distribuição dos elementos radioativos. Rochas com coloração castanha e tonalidades ligeiramente violáceas mostram, em geral, teores mais elevados de $\mathrm{U}_{3} \mathrm{O}_{8}-\mathrm{X}=39,5$ ppm, contrastantes com aquelas de coloração cinza a cinza-acastanhado, cujo conteúdo médio de $\mathrm{U}_{3} \mathrm{O}_{8}$ é da ordem de $21 \mathrm{ppm}$; a média para todas as amostras é de 34,2 ppm $\mathrm{U}_{3} \mathrm{O}_{8}$. Tório exibe variação menos pronunciada, no qual as rochas cinza apresentam média de $217,50 \mathrm{ppm} \mathrm{ThO}_{2}$ e as castanhas, $237,70 \mathrm{ppm}$; a média geral é de $216,70 \mathrm{ppm} \mathrm{ThO}_{2}$. Macroscopicamente, tais variações não se fazem acompanhar por nenhuma mudança na paragênese mineral da rocha, sendo que o que se observa é a maior intensidade da impregnação ferruginosa nas rochas castanhas, onde os teores de $\mathrm{FeO}$ são três vezes superiores aos daquelas com coloração cinza. Isso é consistente, portanto, com a inter-relação entre urânio e ferro (Pinto-Coelho op. cit.).

Alterações na coloração da rocha em função da intensidade da mineralização foram notadas por Gandhi (1978) em riólitos do Canadá, por Narayan Das \& Bhatnagar (1980) em granitos da Índia e por Jacob (1974) em alaskitos uraníferos de Rössing (Namíbia). Nos diques félsicos, o urânio solúvel corresponde a $59,4 \%$ do urânio total e o fixo a $40,6 \%$, relacionando-se, respectivamente, a fases intersticiais e 
Tabela $1 \rightarrow$ Concentraçäo em $\mathrm{U}_{3} \mathrm{O}_{8}$ total, solúvel, fixo e $\mathrm{ThO}_{2}$ de amostras do Granito Serra do Carambet. A sigla $\mathrm{CV}$ se refere a rochas de superficie, e $F$ e $S$ se referem a amostras de subsuperficie. A metodologia analítica empregada se encontra mencionada no texto

\begin{tabular}{|c|c|c|c|c|c|c|c|c|c|c|c|c|c|}
\hline $\begin{array}{l}\text { AMOSTRA } \\
\text { ELEMENTO }\end{array}$ & CV03 & CVO7 & CVO7A & CV11 & CV17 & CV17A & CV25 & $F_{1}, 33,90$ & $\mathrm{~F}_{2} 37,85$ & $F_{2} 50,50$ & $F_{2} 63,65$ & $F_{2} 64,90$ & $F_{2} 68,90$ \\
\hline $\begin{array}{l}\mathrm{U}_{3} \mathrm{O}_{8} \\
\text { TOTAL } \\
\text { (ppm) }\end{array}$ & 8,00 & 7,00 & 9,00 & 5,00 & $11,00^{\circ}$ & 12,00 & 9,00 & 4,00 & 10,00 & 7,00 & 14,00 & 19,00 & 6,00 \\
\hline $\begin{array}{l}\mathrm{U}_{3} \mathrm{O}_{8} \\
\text { SOLUVEL } \\
\text { (ppm) }\end{array}$ & - & 4,80 & 7,12 & 1,50 & 6,20 & 8,04 & 2,70 & 3,29 & 4,19 & 3,83 & 8,02 & 13,52 & 3,83 \\
\hline $\begin{array}{l}\mathrm{U}_{3} \mathrm{O}_{8} \\
\text { FIXO } \\
(\mathrm{ppm})\end{array}$ & - & 2,20 & 1,88 & 3,50 & 4,80 & 3,96 & 6,30 & 0,71 & 5,81 & 3,17 & 5,98 & 5,48 & 2,17 \\
\hline $\begin{array}{l}\mathrm{ThO}_{2} \\
\text { (ppm) }\end{array}$ & $<100$ & $<100$ & $<100$ & $<100$ & $<100$ & $<100$ & $<100$ & $<100$ & $<100$ & $<100$ & $<100$ & $<100$ & $<100$ \\
\hline
\end{tabular}

\begin{tabular}{l|r|r|r|r|r|r|r|r|r|r|r|r|r}
\hline $\begin{array}{l}\text { AMOSTRA } \\
\text { ELEMENTO }\end{array}$ & $\mathrm{S}_{3} 34,90$ & $\mathrm{~S}_{3} 53,45$ & $\mathrm{~S}_{3} 66,15$ & $\mathrm{~S}_{7} 18,90$ & $\mathrm{~S}_{8} 23,50$ & $\mathrm{~S}_{8} 33,50$ & $\mathrm{~S}_{8} 48,25$ & $\mathrm{~S}_{8} 70,50$ & $\mathrm{~S}_{8} 76,70$ & $\mathrm{~S}_{8} 83,25$ & $\mathrm{~S}_{8} 79,15$ & $\mathrm{~S}_{9} 82,70$ & $\mathrm{~S}_{10} 22,70$ \\
\hline $\begin{array}{l}\mathrm{U}_{3} \mathrm{O}_{8} \\
\text { TOTAL } \\
(\mathrm{ppm})\end{array}$ & 12,00 & 8,00 & 5,00 & 14,00 & 8,00 & 5,00 & 11,00 & 9,00 & 8,00 & 5,00 & 26,00 & 19,00 & 7,00 \\
\hline $\begin{array}{l}\mathrm{U}_{3} \mathrm{O}_{8} \\
\text { SOLUVEL } \\
(\mathrm{ppm})\end{array}$ & 9,78 & 5,67 & 4,42 & 12,93 & 6,19 & 3,75 & 6,05 & 7,32 & 4,76 & 3,67 & 17,93 & 18,30 & 3,64 \\
\hline $\begin{array}{l}\mathrm{U}_{3} \mathrm{O}_{8} \\
\begin{array}{l}\mathrm{FIXO} \\
(\mathrm{ppm})\end{array}\end{array}$ & 2,22 & 2,33 & 0,58 & 1,07 & 1,81 & 1,25 & 4,95 & 1,68 & 3,24 & 1,33 & 8,07 & 0,70 & 3,36 \\
\hline $\begin{array}{l}\text { ThO } \\
(\mathrm{ppm})\end{array}$ & $<100$ & $<100$ & $<100$ & $<100$ & $<100$ & $<100$ & $<100$ & $<100$ & $<100$ & $<100$ & 150 & 140 & $<100$ \\
\hline
\end{tabular}

Tabela 2 - Concentração em $U_{3} O_{8}$ total, solúvel, fixo e $\mathrm{ThO}_{2}$ de amostras de subsuperficie dos diques félsicos anômalos

\begin{tabular}{|c|c|c|c|c|c|c|c|c|c|c|c|c|}
\hline $\begin{array}{l}\text { AMOSTŔA } \\
\text { ELEMENTO }\end{array}$ & $F_{1} 54,80$ & $\mathrm{~F}_{2} 77,75$ & $F_{3} 130,15$ & $s_{2} 114,60$ & $S_{3} 16,20$ & $S_{3} 21,35$ & $S_{3} 28,10$ & $S_{3} 45,48$ & $s_{3} 60,50$ & $S_{8} 141,90$ & $S_{0} 80,20$ & $s_{9} 109,80$ \\
\hline $\begin{array}{l}\mathrm{U}_{3} \mathrm{O}_{8} \\
\text { TOTAL } \\
\text { (ppm) }\end{array}$ & 56,00 & 48,00 & 30,00 & 21,00 & 2310,00 & 18,00 & 49,00 & 24,00 & 36,00 & 50,00 & 21,00 & 23,00 \\
\hline $\begin{array}{l}\mathrm{U}_{3} \mathrm{O}_{8} \\
\text { SOLUUVEL } \\
\text { (ppm) }\end{array}$ & 36,08 & 34,27 & 21,55 & 3,70 & 2306,28 & 14,15 & 29,54 & 19,11 & 29,14 & 27,84 & 15,56 & - \\
\hline $\begin{array}{l}\mathrm{U}_{3} \mathrm{O}_{8} \\
\mathrm{FIXO} \\
\text { (ppm) }\end{array}$ & 19,92 & 13,73 & 8,45 & 17,30 & 3,72 & 3,85 & 19,46 & 4,89 & 6,86 & 22,16 & 5,44 & - \\
\hline $\begin{array}{l}\mathrm{ThO}_{2} \\
\text { (ppm) }\end{array}$ & 270,00 & 240,00 & 250,00 & 180,00 & 230,00 & 220,00 & 210,00 & 240,00 & 220,00 & 310,00 & 110,00 & 120,00 \\
\hline
\end{tabular}

secundárias, e a minerais acessórios como zircão e allanita.

DISTRIBUIÇÃO DE RADIOELEMENTOS O urânio, elemento geoquimicamente litófilo, tende a acompanhar o trend de diferenciação magmática, em que as maiores concentraçöes se relacionam às rochas com conteúdos elevados em $\mathrm{SiO}_{2}$. Durante o desenvolvimento evolutivo dos processos magmáticos, tanto o $\mathrm{U}$ quanto 0 Th se acumulam nos diferenciados ácidos e alcalinos enriquecidos em $\mathrm{Na}$ e K, e saturados em componentes volateis, nos quais o urânio apresenta maior mobilidade que o torio e, conseqüentemente, migra com maior facilidade, permanecendo associado a diferenciados residuais ou escapando juntamente com as fraçōes pós-magmáticas; o tório permanece de preferência retido na fusäo (Turovskii 1957, Wedepohl 1969).

Encontrado sob a forma de traços em vários minerais, o urânio é mais concentrado em poucas espécies mineralógicas. $O$ processo de sua incorporaçăo aos principais minerais formadores de rocha, como quartzo e feldspato, permanece obscuro, embora possam ser aventadas as seguintes possibilidades: a. substituição isomórfica no retículo cristalino; b. concentração ao longo de imperfeiçōes; c. adsorção pelas imperfeiçőes cristalinas e nos bordos dos grãos; e d. inclusões como microcristais de minerais de urânio (Wedepohl op. cit.).

Além de se associar a minerais essenciais, o urânio (e o tório) se encontra, em geral, em grãos de acessórios, isolados ou inclusos nos minerais essenciais. Os principais concentradores deste elemento são zircão, titanita, allanita, apatita, epídoto, monazita, rutilo, anatásio, leucoxênio, fluorita, ilmenita e magnetita (Berzina et. al. 1974).

No Granito Serra do Caramber foram identificados nos testes autorradiomicrográficos traços de partículas $\alpha$ em feldspato potássico, restritos a superff́cies de clivagens e microfraturas, porém sempre com baixa densidade em virtude das modestas concentraçôes em $\mathrm{U}_{3} \mathrm{O}_{8}$. Nos diques félsicos não se observou a presença de partículas radioativas associadas a minerais essenciais. Nos estudos autorradiomicrográficos realizados em amostras do granito verificou-se a emissão de traços $\alpha$ associados a cristais de xenotima, com bordos 
corroídos e microinclusões de minerais opacos (Fotomicrografias 1a e 1b). A xenotima ocorre no granito em porcentagens modais pouco significativas, sendo de preferência encontrada em seçăo basal. Devido à radioatividade, e comum observar-se um mascaramento da coloração e de certas propriedades 6pticas deste mineral. Entretanto, em gräos menos alterados, o índice de refração e a birrefringência conduziram à sua identificaçăo.

Nos diques félsicos foram detectados traços $\alpha$ apenas em gráos de zircăo parcial ou totalmente metamictizados (Fotomicrografias lc e 1d). O mineral ocorre como diminutas pontuações com colorações castanhas preservando algumas vezes um núcleo desprovido de impregnaçöes ferruginosas; estas segregaçöes se assemelham aos hot spots descritos por Zielinski et. al. (1980) em tutos zeolitizados dos Estados Unidos.

O zircāo dos diques foi analisado por microscopia eletrônica de varredura (MEV), utilizando-se a técnica de elétrons retrodifundidos. A análise por fluorescência de raios $X$ revelou a presença de $\mathrm{Th}$, com pequena quantidade de $\mathrm{Hf} e$ Fe.

Outro ponto da rocha analisado por esta técnica (Fotomicrografia 2a) mostra, no espectro de fluorescência de raios $\mathrm{X}$, a presença de $\mathrm{Th}, \mathrm{Fe}, \mathrm{Ca}, \mathrm{Si}, \mathrm{Al}$ e ETR (Ce e Nd), indicando a presença de allanita. A repartição do Th pode ser vista na imagem eletrônica da fotomicrografia $2 b$, em que as porçôes com maior acúmulo de pontos com coloraçôes

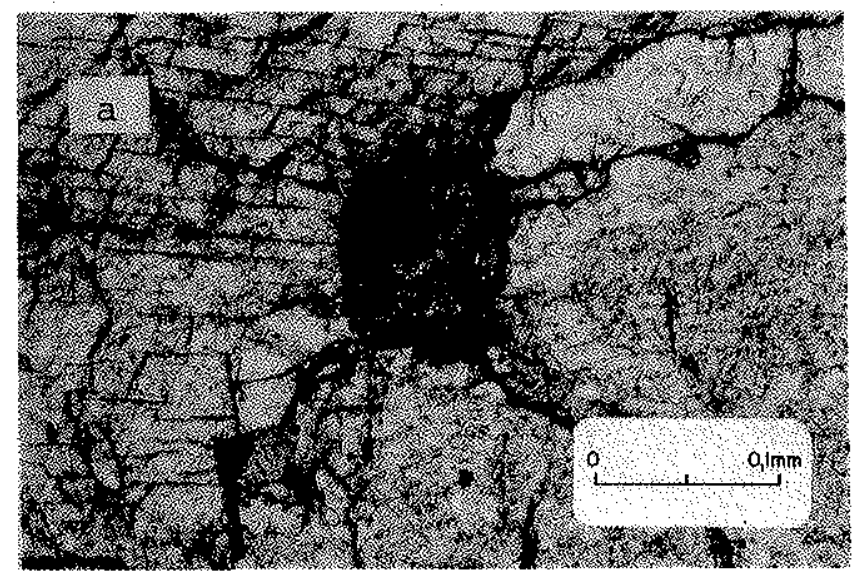

cinza-claras representam os sítios preferenciais de localizaçấo deste elemento, ou seja, o Th tende a se concentrar em maiores quantidades nos bordos do cristal de allanita.

Outra forma de ocorrência de urânio em rochas graníticas, além dos minerais essenciais e dos resistatos primários, é a que se concentra ao longo de superfícies de fraturas, contatos "entre os cristais, zonas de alteração, dissolução em inclusões fluidas e fluidos intergranulares, normalmente designada urânio intergranular ou intersticial (Zielinski op. cit., Tieh $e t$ al. 1980, Speer et al. 1981), facilmente removida da rocha hospedeira. Wilson (1977) (apud Zielinski op. cit.) classifica o urânio intersticial em dois tipos: a. primáriọ: desenvolve-se a partir do limite entre os cristaís, em clivagens, defeitos no retículo cristalino, sendo distribuído, provavelmente, por fluidos metamórficos ou hidrotermais; e b. secundário: adsorvido em água subterrânea por produtos de alteraçắo secundária como óxidos hidratados de Fe-Mn-Ti.

No Granito Serra do Carambeŕ, o urânio intersticial, que representa a maior parte do elemento presente na rocha, como ja se comentou, ocorre principalmente sob a forma primária, considerando-se a classificação supramencionada, sobretudo ao longo de planos de clivagens de feld́spato potássico e no contato entre os minerais essenciais.

Observou-se, ainda, baixa densidade de traços a associados a superfícies de clivagens de biotitas alteradas $\mathrm{e}$, ainda, a minerais opacos (magnetita) inclusos nos mesmos. A presença de clorita, ao que tudo indica, não desempenhou

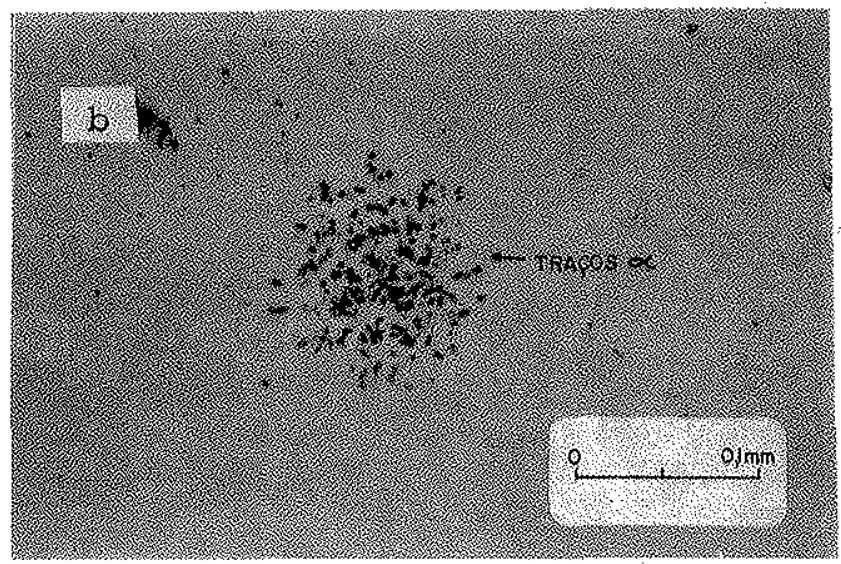

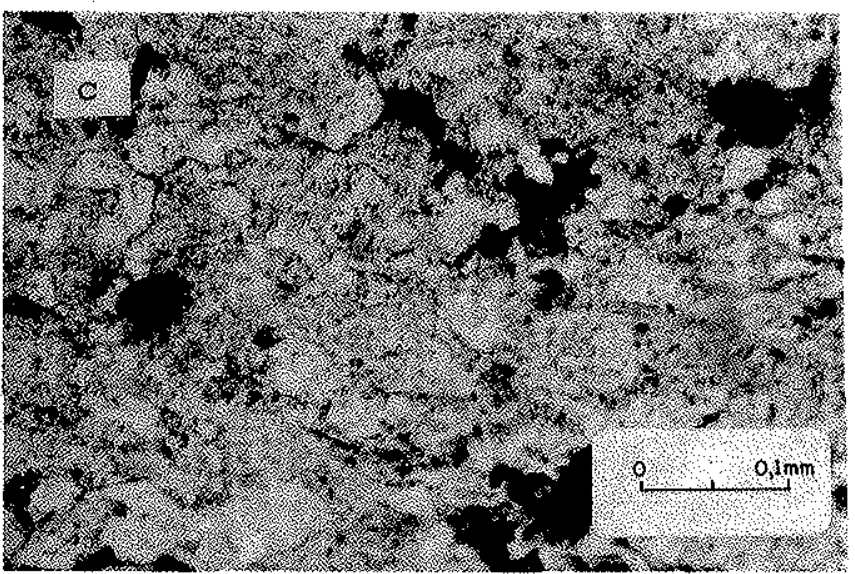

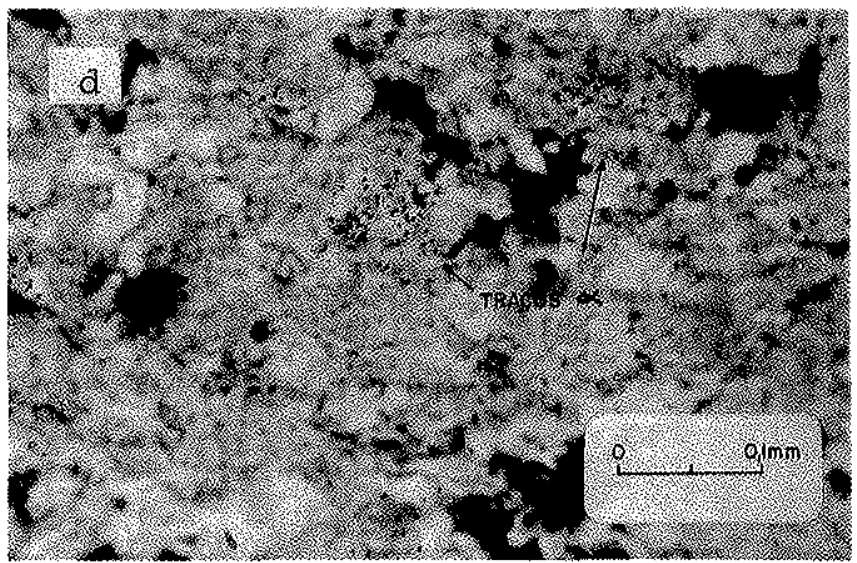

Fotomicrografia 1 - a. Cristal de xenotima incluso em feldspato potássico originando fraturas radiais, Granito Serra do Carambel. Nicóis paralelos. b. Traços de radiação a emitidos pelo cristal da fotomicrografia anterior. Nicóis paralelos. c. Opacos pontuais (zircäo) metamictizados e impregnados por bxidos de ferro. Dique félsico associado ao Granito Serra do Carambel. A matriz da rocha tem composição quartzo-feldspática. Nicois paralelos. d. Traços de particulas a emitidos pelos minerais da fotomicrografia anterior. Verifica.se ligeiro deslocamento do detector para a esquerda. Nicóis paralelos 
funçâo importante na distribuição de radioelementos, uma vez que amostras de granito com quantidades acentuadas deste mineral exibem teores médios de $\mathrm{U}_{3} \mathrm{O}_{8}$ semelhantes, por vezes inferiores, àquelas em que a sua presença se dá de forma pouco significativa.

Além dos minerais opacos associados à biotita, notam-se, neste granito, cristais alterados de ilmenita com manchas de coloração castanho-avermelhada e amarelada, dispostos entre os constituintes da rocha, parcialmente translúcidos (Fotomicrografia 2c) e que fornecem grande densidade de traços $\alpha$ (Fotomicrografia 2d). Este mineral foi identificado pelo exame ao estereomicroscópio e de testes de microquímica qualitativa. Observa-se que sua radioatividade nāo se distribui de forma homogênea ao longo do cristal, havendo locais onde não se dá a emissão de partículas $\alpha$. Baixa densidade de emissão foi, por outro lado, diagnosticada em grâos opacos com hábito idiomórfico (pirita?). Não obstante as diversas técnicas empregadas, não foi identificado nenhum mineral primário de urânio. Entretanto, năo deve ser totalmente inviabilizada a possibilidade da existência de microinclusões de uraninita ou pechblenda em constituintes mineralógicos do granito e dos diques associados.

A utilização de diagramas bivariados, considerando-se tão-somente as concentraçồes de $\mathrm{U}_{3} \mathrm{O}_{8}$ em relação a elementos maiores ou traços do granito em questão, mostrou-se pouco funcional, sobretudo devido à grande dispersão dos valores analíticos encontrados. Em consequếncia, na maior parte dos casos, poder-se-iam inferir
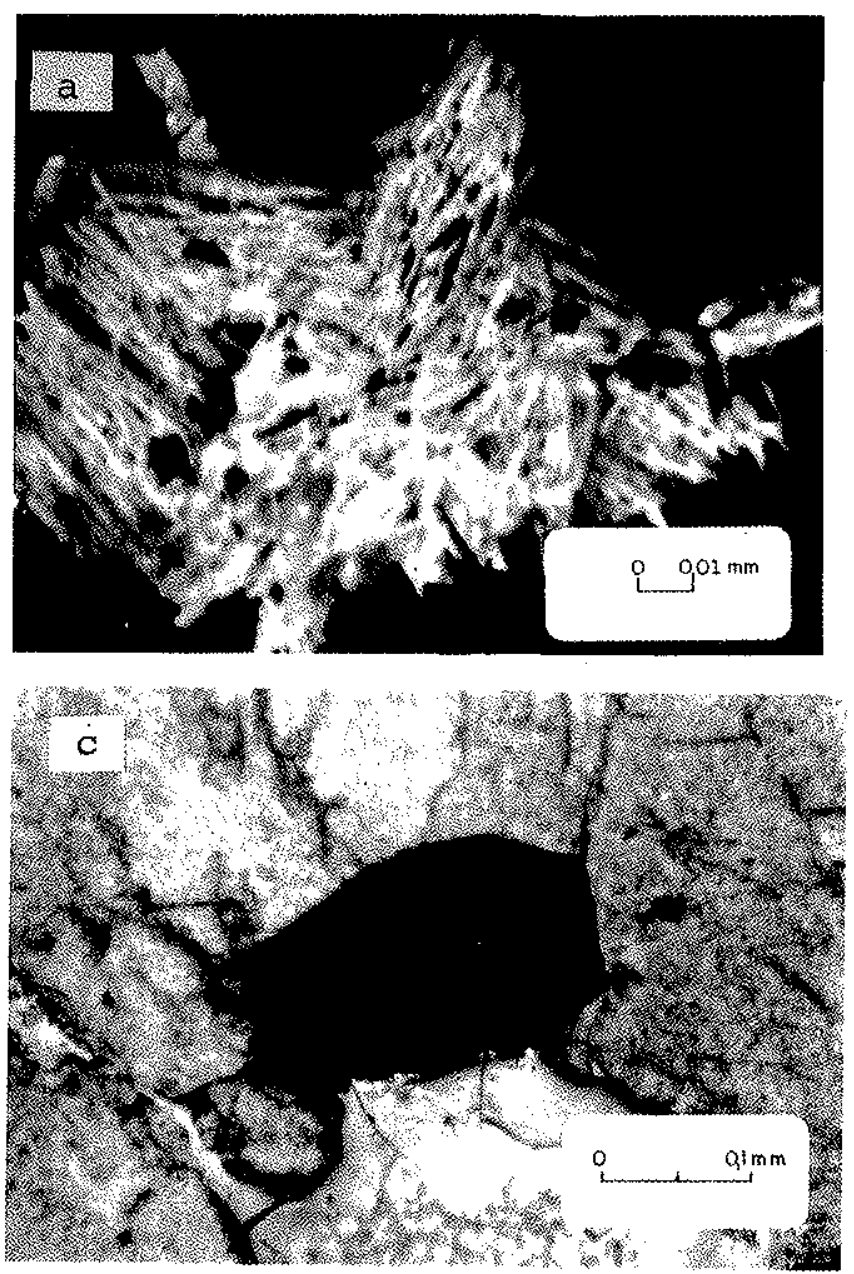

trends opostos entre si no mesmo gráfico, comprometendo assim os resultados interpretativos. As maiores dispersōes foram observadas justamente no urânio. Segundo Padma Kumari et al. (1977) e Ragland at al. (1967), o controle secundário da incorporação do urânio, causado por processos oxidantes ativos nos estágios finais da fusăo granítica, tem sido empregado parà explicar sua dispersão, na qual a distribuiçăăo errática se deve às elevadas pressöes de oxigênio no magma.

Para minimizar esta deficiência, optou-se pela construçăo de matrizes de correlaçāo e respectivos dendrogramas, empregando-se os 6xidos e alguns elementos-traços do Granito Serra do Carambeí; tal procedimento não foi utilizado para os diques félsicos em virtude de o número de amostras analisadas ser inferior ao mínimo de 30 , tido como de maior representatividade estatística e tambem devido ao fato de vários elementos maiores se situarem muito próximo ao limite de detecção inferior do método analítico empregado, o que comprometeria os resultados finais. A descrição detalhada do método de matrizes e dendrogramas encontra-se em Davis (1973).

$\mathrm{Na}$ figura 2 observa-se o dendrograma resultante da matriz de correlaçăo entre elementos maiores e traços do granito em discussão; os valores'dos coeficientes de correlação acham-se na Tabela 3.

Năo obstante sua maior eficácia em relação aos diagramas bivariados, tal matriz deve ser encarada aqui com certa prudência, uma vez que as informaçőes retiradas da mesma e
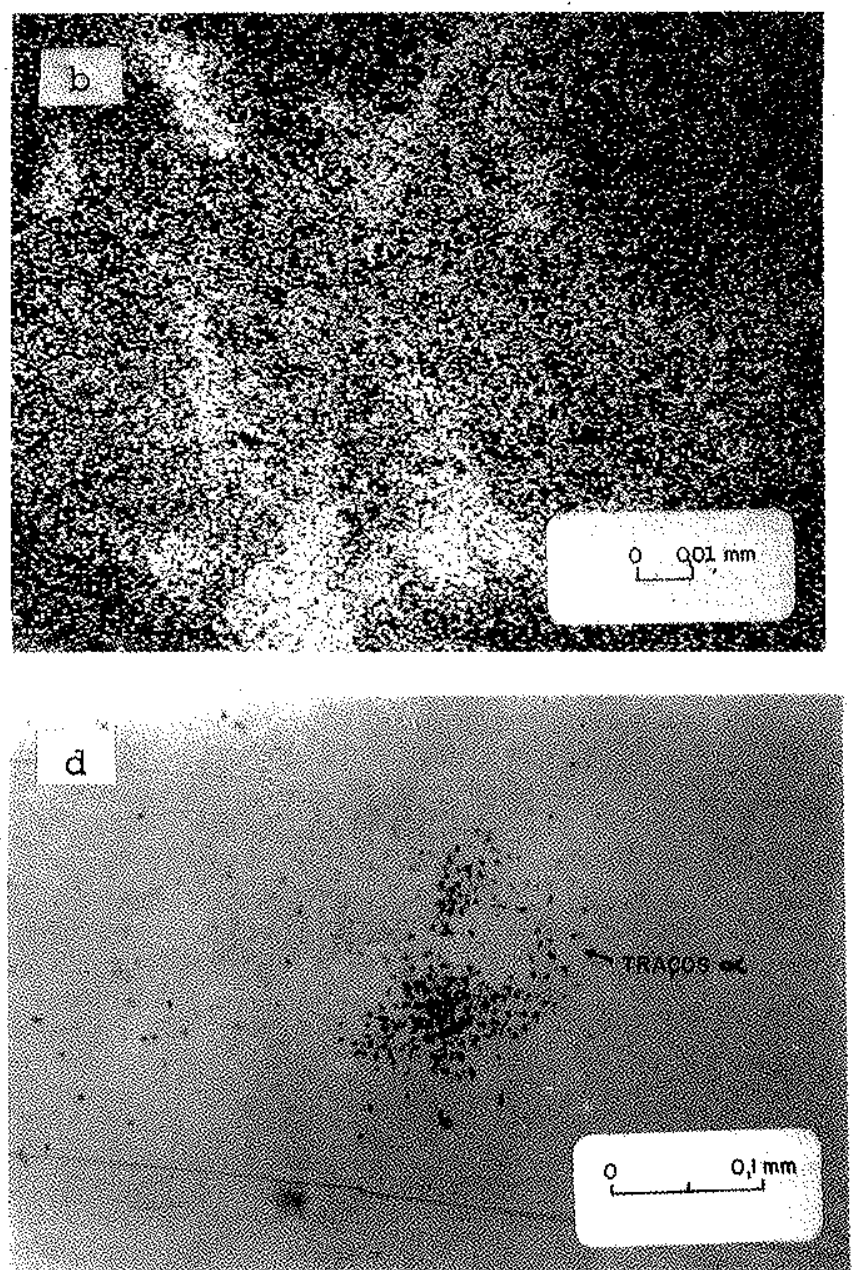

Fotomicrografia 2 - a. Imagem por eletrons retrodifundidos de allanita portadora de $\mathrm{Th}, \mathrm{Fe}, \mathrm{Ca}, \mathrm{Si}, \mathrm{Al}$, Ce e Nd. Dique felsico intrusivo no Granito Serra do Carambet. Fotografia cedida por L. Izoret. b. Repartição de tório na fase mineral da fotomicrografia anterior, cedida por L. Izoret. c. Cristal de ilmenita parcialmente translúcida, inclusa em feldspato potassico do Granito Serra do Carambet. Nicois paralelos. d. Traços de particulas $\alpha$ emitidos pelo mineral da fotomicrografia anterior. Nicóis paralelos 


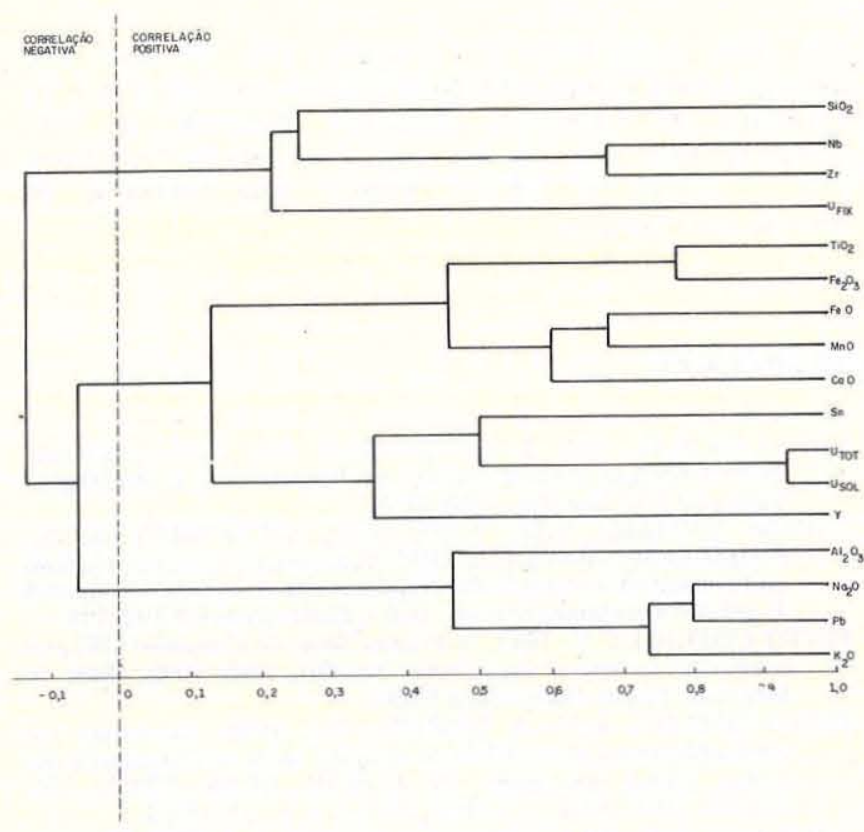

Figura 2 - Dendrograma resultante da matriz de correlação entre elementos maiores e traços do Granito Serra do Carambet

do dendrograma nâo assumem caráter definitivo, devendo ser tratadas dentro de um contexto lógico, respaldado por dados petrográficos e petroquímicos.

A partir do exame desses dados, nota-se que o urânio total apresenta fraça correlação positiva $(0,0874)$ com $\mathrm{SiO}_{2}$ e $\mathrm{K}_{2} \mathrm{O}$ $(0,0029)$; com os demais óxidos, a correlação é negativa. Em relação aos elementos-traços, verifica-se correlação positiva apenas con $\mathrm{Sn}(0,04322), \mathrm{Y}(0,2637)$ e $\mathrm{U}_{3} \mathrm{O}_{8}$ solúvel, esta última bastante elevada $(0,9262)$. Tal comportamento pode ser atribuído à concentração do elemento radioativo em xenotina. A elevada razão urânio solúvel/urânio total em rochas ígneas - no caso do Granito Serra do Carambeí a média global é de 0,69 - é, segundo Kotopouli et al. (1982), indicativa de alteração deutérica ou atividade hidrotermal.

$\mathrm{O}$ urânio fixo se correlaciona positivamente com $\mathrm{Zr}, \mathrm{Nb}$, $\mathrm{SiO}_{2}$ e $\mathrm{K}_{2} \mathrm{O}$ (Fig. 2 e Tab. 3), consistente desta maneira com a sua concentração em minerais acessórios resistatos como xenotina e zircâo no líquido leucocrático residual rico em $\mathrm{SiO}_{2}$ e $\mathrm{K}_{2} \mathrm{O}$. A correlação positiva, da ordem de 0,2637 e 0,3745 entre urânio total e solúvel, respectivamente, e Y, é compatível com a concentração deste elemento em xenotina.

A existência de traços de partículas $\alpha$ associados a feldspato potássico deste granito é confirmada aqui pela fraca correlação positiva $(0,0029)$ verificada entre urânio total e $\mathrm{K}_{2} \mathrm{O}$. Embora não se tenha identificado a presença de traços $\alpha$ associados ao zircão, a correlação positiva entre $\mathrm{Zre} \mathrm{U}_{3} \mathrm{O}_{8}$ fixo $(0,1090)$ permite supor a existência deste elemento radioativo incorporado à estrutura do mineral; a associação entre ambos é usual, sendo comumente observada a substituiçåo do $\mathrm{U}$ por $\mathrm{Zr}$ na estrutura da pechblenda (Forbes et al. 1984).

A correlação entre $\mathrm{TiO}_{2}, \mathrm{Fe}_{2} \mathrm{O}_{3}, \mathrm{FeO}, \mathrm{MnO}$ e $\mathrm{CaO}$ (Fig. 2) refere-se, provavelmente, à titanita, acessório comum no plúton em discussão. Correlação positiva verificada entre urânio solúvel e $\mathrm{Fe}_{2} \mathrm{O}_{3}$ faz supor que as microfissuras anastomosadas freqüentemente encontradas em feldspato potássico deste granito e preenchidas por material castanho-avermelhado contenham, além de 6́xidos/hidróxidos de ferro, elementos radioativos (Pinto-Coelho 1986).

CONCLUSÃO O conteúdo total de urânio existente no Granito Serra do Carambeí e nos diques félsicicos associados está representado pela somatória de: a. urânio contido em minerais alterados (biotita); b. urânio em fases mineralógicas acessórias (xenotima, zircâo, ilmenita); e c. urânio presente sob a forma de fases intersticiais ou intergranulares, que nos dois tipos lítológicos compreende as maiores concentrações do elemento.

A homogeneidade na distribuição dos álcalis (Pinto-Coelho op. cit.), excetuando-se, evidentemente, as variações devidas a processos intempéricos, é compatível com a formação dos diques félsicos a partir de processos ígneos primários, aos quais não foram superimpostos fenômenos secundários de metassomatismo com efeito marcante em seu quimismo. As concentrações de urânio encontradas nessas rochas se devem simplesmente ao enriquecimento do metal no resíduo final durante o processo de cristalização magmática.

A existência de correlação positiva entre urânio e elementos-traços imóveis como $\mathrm{Y}, \mathrm{Zr}$ e $\mathrm{Nb}$ é consistente com a concentração do metal de preferência em minerais acessórios.

Agradecimentos A Gilmar Paiva Lima, gerente de

Tabela 3 - Matriz de correlação entre elementos maiores e traços do Granito Serra do Carambet

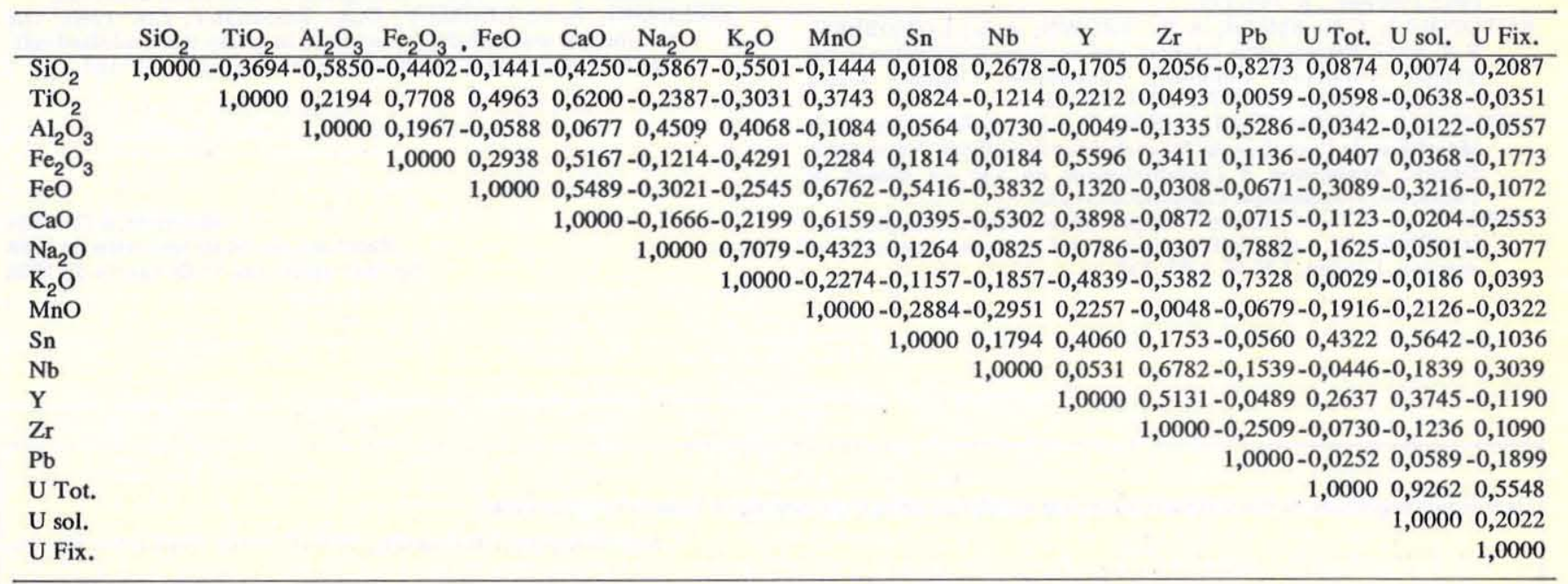


Apoio Técnico e Desenvolvimento Tecnológico da Mineropar, por tornar possível a elaboraçäo deste artigo; à datilógrafa Ana Maria Gapiski e à desenhista Roseneide Ogleari Gonçalves; aos professores da Universidade de Brasília O.J. Marini, eterno orientador, pela leitura do manuscrito e sugestöes apresentadas, e $H$. Jost, pelo auxílio no tratamento dos dados estatísticos; à Nuclebrás, pela liberação dos testemunhos de sondagem e análises químicas efetuadas; a $\mathrm{K}$. Fuzikawa, da Nuclebrás, Escritório Regional de Belo Horizonte, pela realização dos testes autorradiomicrográficos, e a L. Izoret, do BRGM, França, pela realização da microscopia eletrônica.

\section{REFERÊNCIAS BIBLIOGRÁFICAS}

BERZINA, I.G.; YELISEYEVA, O.P.; POPENKO, D.P. 1974. Distribution relationships of uranium in intrusive rocks of Northern Kazakhastan. Int. Geol. Rev.16:1 1.91-1204.

BOWIE, S.H.U. 1951. Autoradiographic techniques in geological research. Bull. Geol. Survey Great Britainl, v.3, p.58-79.

BRANDÃO, P.M.C. 1984. Uso de detectores plásticos em estudos autorradiomicrograficos de minerais radioativos da Província Uranifera de Lagoa Real,.BA. In: CONGR. BRAS. GEOL., 33, Rio de Janeiro, 1984. Anais... Rio de Janeiro, SBG. v.3, p.1518-1529.

CHAROY, B. 1979. Définition et importance des phénomènes deutériques et des fluides associés dans les granites: conséquences métallogéniques. Sciences de la Terre, Mém 37, 364 p.

COPPENS, R.; RICHARD, M.; RICHARD, P. 1979, Utilisations comparés des emulsions photographiques nucleares et des films de nitrate de cellulose dans letude des rayons $\alpha$ em géologi et minéralogie, s.n.t.

DARNLEY, A.G. 1982. "Hot" granites: some general remarks. In: MAURICE, Y.T. ed. Uranium in granites. Geol. Surv. Canada, paper 81.23 p. $1-10$.

DAVIS, J.C. 1973. Statistics and data analysis in geology. New York, John John Wiley \& Sons Inc. p. 456 473.

DE LA ROCHE, H.; LETERRIER, J.; GRANDCLAUDE, P.; MARCHAL, M. 1980. A Classification of volcanic and plutonic rocks using $R_{1} R_{2}$ - diagram and major- element analyses -its relationships with current nomenclature. Chem. Geol. 29: 183-211.

FORBES, P.; PACOUET, A.; CHANTRET, F; OUMAROU, J.; PAGEL, M. 1984. Marqueurs du volcanisme dans le gisement d'uranium d'Akonta (République du Niger). C.R. Acad. Sc. Paris, t. 298 , série II no 15 , p. $647-650$.

GANDHI, S.S, 1978. Geological setting and genetic aspects of uranium occurrences in the Kaipokok Bay, Big River area, Labrador. Econ. Geol. 73:1492-1522.

HAUSEUX, M.A. 1977. Mode of uranium occurrence in a migmatitic granite terrain, Baie Johan Beetz, Quebec. Can. Min. Metal. Bull., p.110-116.

HOUSTON, S.M. \& JEFFERIES, N.L. 1982. CR-39 $\alpha$ - Particle autoradiographs of some radioactive minerals from SW England. INTERNATT. CONF, BRISTOL ON SOLID STATE NUCLEAR TRACK DETECTORS, Bristol, 1982 Proceed... Bristol. p.621-625.

JACOB, R.E, 1974. The radioactive mineralisation in part of the Central Damara Belt, South West Africa, and its possible origin. At. En. Board S. Afr. Rep. PIN-234 (BR), 17 p.

KHADDURI, I.Y. 1982 . On the use of cellulose nitrate film for uranium exploration. In: INTERNAL, CONF, BRISTOL ON SOLID STATE NUCLEAR TRACK DETECTORS. 11, Bristol, 1982. Proceed... p. 785.797.

KOTOPOULI, C.N. SMITH, A.Y.; BROWN, A.A.; LUNDBERG, B.R. 1982. Petrographic relations and uranium distribution in the Skaloti Granitoid Complex, Paranestion District, Greek Macedonia. Econ. Geol. 77:1787-1892.892.

KWINTA, J.; DEMANGE, J.; MICHAEL, J.J, 1980. Etude de la repartition de l'uranium das les roches par la méthode des traces de fission. Application a lechantillonage en vue du dosage de I'uranium. J. Radioanal. Chem. 55:233-252.

MOREAU,M. 1977. L'uranium et les granit6ides: essai d'interpretation In: JONES, M.J. ed. Geology, mining and extractive processing of uranium. London, I.M.M. p.83-102.
NARAYAN DAS, G.R. \& BHATNAGAR, G.S. 1981. Uraninitefluorite-bearing sheared granites of Brijrani Gad in Bhilangana Valley (U.P.). Geol. Soc. India 22:247.

PADMA KUMARI, V.M.; RAO, N.V.; SITARAMAYYA, S.; BHIMASANKARAM, L.S, 1977. Variation of uranium, thorium and potassium contents in the granitic rocks of Hyderabad, Andhra Pradesh - a preliminary study. Ind. J. Earth Science 4:192-196.

PINTO-COEL HO, C.V. 1982, O Granito Serra do Carambet (PR) e as anomalias uraniferas associadas. Brasfila, UnB 309p. (Tese de Mestrado, Depto. Geociências UnB).

PINTO-COELHO, C.V. \& MARINI, O.J, 1986. Assinatura em elementos terras-raxas (ETR) do Granito Serra do Caramber e das rochas ígneas associadas. In: CONGR. BRAS, GEOL., 34, Goiânia, 1986. Anais... Goiânia, SBG. v.3, p.1311-1321.

RAGLAND, P.C.; BILLINGS, G.K.; ADAMS, A.S. 1967. Chemical fractionation and its relationship to the distribution of thorium and uranium in a zoned granite batholith. Geoch. Cosmoch. Acta 31:17:33.

SIMPSON, P.R.; PLANT, J.; COPE, M.J. 1976. Uranium abundance and distribution in some granites from northern Scotland and south west England as indicators of uranium provinces. In: Geology, minig and extractive processing of uranium. JONES, M.J. ed. London. IMM, p.126-136.

SPEER, J.A.; SOLBERG, T.N.; BECKER, S.W, 1981. Petrography of the uranium-bearing minerais of the Liberty Hill Pluton, South Carolina: phase assemblages and migration of uranium in granitoid rocks. Econ. Geol. 76:2162-2175.

STRECKEISEN, A. 1976. To each plutonic rock its proper name. Earth Sci.Rev. (12):1-33.

TAMMEMAGI, H.Y.\& SMITH, N.L. 1975. A radiogeologic study of the granites of SW England. J. Geol. Soc. London 131:415-427.

TIEH, T.T.; LEDGER, E.B.; ROWE, M.W. 1980. Release of uranium from granitic rocks during in situ weathering and initial erosion (Central Texas). Chem. Geol. (29):227-248:

TUROVSKII, S.D. 1957. Distribution of radioactive elements in intrusive rocks of northerm Kirgizia. Geochemistry 2:199-215.

TUTTLE, O.F. \& BOWEN, N.L. 1958. Origin of granite in the light of experimental studies in the system

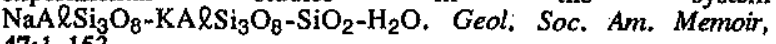
47:1-153.

WEDEPOHL, K.H. 1969. Handbook of Geochemistry. Vol, II.1, sec. 90 and 92. Berlin, Heidelberg and New York. Springer-Verlag.

WRIGHT, J.B. 1969. A simple alkalinity ratio and its application to questions of non-orogenic granite genesis. Geol. Mag. 106:370-384

ZIELINSKI, R.A. 1979. Uranium mobility during interaction of rhyolitic obsidian, perlite and felsite with alkaline carbonate solution: $\mathrm{T}=120^{\circ} \mathrm{C}, \overline{\mathrm{P}}=210 \mathrm{~kg} / \mathrm{cm}^{2}$. Chem. Geol. $27: 47-63$.

ZIELINSKI, R.A.; LINDSEY, D.A.; ROSHOLT, J.N. 1980. The distribution and mobility of uranium in glassy and zeolitized tuff, Keg Mountain area, Utah, USA. Chem. Geol. (29):139-162.

MANUSCRITO 524

Recebido em 24 de fevereiro de 1988 Revisăo aceita em 11 de agosto de 1988 